\title{
Practice parameters for determining brain death in adults (Summary statement)
}

\author{
Report of the Quality Standards Subcommittee of the American Academy of Neurology
}

Overview. Brain death is defined as the irreversible loss of function of the brain, including the brainstem. Brain death from primary neurologic disease usually is caused by severe head injury or aneurysmal subarachnoid hemorrhage. In medical and surgical intensive care units, however, hypoxic-ischemic brain insults and fulminant hepatic failure may result in irreversible loss of brain function. In large referral hospitals, neurologists make the diagnosis of brain death 25 to 30 times a year.

Justification. Brain death was selected as a topic for practice parameters because of the need for standardization of the neurologic examination criteria for the diagnosis of brain death. Currently, there are differences in clinical practice in performing the apnea test and controversies over appropriate confirmatory laboratory tests. This document outlines the clinical criteria for brain death and the procedures of testing in patients older than 18 years.

Description of the process. All literature pertaining to brain death identified by MEDLINE for the years 1976 to 1994 was reviewed. The key words "brain death" and "apnea test" (subheading, "adult") were used. Peer-reviewed articles with original work were selected. Current textbooks of neurology, medicine, pulmonology, intensive care, and anesthesia were reviewed for opinion. On the basis of this review and expert opinion, recommendations are presented as standards, guidelines, or options. The recommendations in this document are guidelines unless otherwise specified (see boxed Definitions at end).

\section{Diagnostic criteria for clinical diagnosis of} brain death

A. Prerequisites. Brain death is the absence of clinical brain function when the proximate cause is known and demonstrably irreversible.

1. Clinical or neuroimaging evidence of an acute CNS catastrophe that is compatible with the clinical diagnosis of brain death

2. Exclusion of complicating medical conditions that may confound clinical assessment (no severe electrolyte, acid-base, or endocrine disturbance)

3. No drug intoxication or poisoning

4. Core temperature $\geq 32^{\circ} \mathrm{C}\left(90^{\circ} \mathrm{F}\right)$

$B$. The three cardinal findings in brain death are coma or unresponsiveness, absence of brainstem reflexes, and apnea.

1. Coma or unresponsiveness-no cerebral motor response to pain in all extremities (nail-bed pressure and supraorbital pressure)

2. Absence of brainstem reflexes a. Pupils

(i) No response to bright light

(ii) Size: midposition $(4 \mathrm{~mm})$ to dilated $(9$ $\mathrm{mm}$ )

b. Ocular movement

(i) No oculocephalic reflex (testing only when no fracture or instability of the cervical spine is apparent)

(ii) No deviation of the eyes to irrigation in each ear with $50 \mathrm{ml}$ of cold water (allow 1 minute after injection and at least 5 minutes between testing on each side)

c. Facial sensation and facial motor response

(i) No corneal reflex to touch with a throat swab

(ii) No jaw reflex

(iii) No grimacing to deep pressure on nail bed, supraorbital ridge, or temporomandibular joint

d. Pharyngeal and tracheal reflexes

(i) No response after stimulation of the posterior pharynx with tongue blade

(ii) No cough response to bronchial suctioning

See also page 1003

Approved by the Quality Standards Subcommittee July 20, 1994. Approved by the Practice Committee July 29, 1994. Approved by the Executive Board September 24, 1994 .

Address correspondence and reprint requests to Joanne F. Okagaki, American Academy of Neurology, Suite 335, 2221 University Ave., SE, Minneapolis, MN 55414. The background paper by Dr. Eelco F.M. Wijdicks, published in this issue, is also available upon request from the American Academy of Neurology office (612/623-2439). 
3. Apnea-testing performed as follows:

a. Prerequisites

(i) Core temperature $\geq 36.5^{\circ} \mathrm{C}$ or $97^{\circ} \mathrm{F}$

(ii) Systolic blood pressure $\geq 90 \mathrm{~mm} \mathrm{Hg}$

(iii) Euvolemia. Option: positive fluid balance in the previous 6 hours

(iv) Normal $\mathrm{PCO}_{2}$. Option: arterial $\mathrm{PCO}_{2}$ $\geq 40 \mathrm{~mm} \mathrm{Hg}$

(v) Normal $\mathrm{PO}_{2}$. Option: preoxygenation to obtain arterial $\mathrm{Po}_{2} \geq 200 \mathrm{~mm} \mathrm{Hg}$

b. Connect a pulse oximeter and disconnect the ventilator.

c. Deliver $100 \% \mathrm{O}_{2}, 6 \mathrm{l} / \mathrm{min}$, into the trachea. Option: place a cannula at the level of the carina.

d. Look closely for respiratory movements (abdominal or chest excursions that produce adequate tidal volumes).

e. Measure arterial $\mathrm{PO}_{2}, \mathrm{PCO}_{2}$, and pH after approximately 8 minutes and reconnect the ventilator.

f. If respiratory movements are absent and arterial $\mathrm{PCO}_{2}$ is $260 \mathrm{~mm} \mathrm{Hg}$ (option: 20 $\mathrm{mm} \mathrm{Hg}$ increase in $\mathrm{PCO}_{2}$ over a baseline normal $\left.\mathrm{PCO}_{2}\right)$, the apnea test result is positive (ie, it supports the diagnosis of brain death).

g. If respiratory movements are observed, the apnea test result is negative (ie, it does not support the clinical diagnosis of brain death), and the test should be repeated.

h. Connect the ventilator if, during testing, the systolic blood pressure becomes $\leq 90$ $\mathrm{mm} \mathrm{Hg}$ or the pulse oximeter indicates significant oxygen desaturation and cardiac arrhythmias are present; immediately draw an arterial blood sample and analyze arterial blood gas. If $\mathrm{PCO}_{2}$ is $\geq 60$ $\mathrm{mm} \mathrm{Hg}$ or $\mathrm{PCO}_{2}$ increase is $\geq 20 \mathrm{~mm} \mathrm{Hg}$ over baseline normal $\mathrm{PCO}_{2}$, the apnea test result is positive (it supports the clinical diagnosis of brain death); if $\mathrm{PCO}_{2}$ is $<60$ $\mathrm{mm} \mathrm{Hg}$ or $\mathrm{PCO}_{2}$ increase is $<20 \mathrm{~mm} \mathrm{Hg}$ over baseline normal $\mathrm{PCO}_{2}$, the result is indeterminate, and an additional confirmatory test can be considered.

\section{Pitfalls in the diagnosis of brain death}

The following conditions may interfere with the clinical diagnosis of brain death, so that the diagnosis cannot be made with certainty on clinical grounds alone. Confirmatory tests are recommended.

A. Severe facial trauma

B. Preexisting pupillary abnormalities

C. Toxic levels of any sedative drugs, aminoglycosides, tricyclic antidepressants, anticholinergics, antiepileptic drugs, chemotherapeutic agents, or neuromuscular blocking agents

D. Sleep apnea or severe pulmonary disease resulting in chronic retention of $\mathrm{CO}_{2}$
III. Clinical observations compatible with the diagnosis of brain death

These manifestations are occasionally seen and should not be misinterpreted as evidence for brainstem function.

A. Spontaneous movements of limbs other than pathologic flexion or extension response

B. Respiratory-like movements (shoulder elevation and adduction, back arching, intercostal expansion without significant tidal volumes)

C. Sweating, blushing, tachycardia

D. Normal blood pressure without pharmacologic support or sudden increases in blood pressure

E. Absence of diabetes insipidus

F. Deep tendon reflexes; superficial abdominal reflexes; triple flexion response

G. Babinski reflex

\section{Confirmatory laboratory tests (Options)}

Brain death is a clinical diagnosis. A repeat clinical evaluation 6 hours later is recommended, but this interval is arbitrary. A confirmatory test is not mandatory but is desirable in patients in whom specific components of clinical testing cannot be reliably performed or evaluated. It should be emphasized that any of the suggested confirmatory tests may produce similar results in patients with catastrophic brain damage who do not (yet) fulfill the clinical criteria of brain death. The following confirmatory test findings are listed in the order of the most sensitive test first. Consensus criteria are identified by individual tests.

A. Conventional angiography. No intracerebral filling at the level of the carotid bifurcation or circle of Willis. The external carotid circulation is patent, and filling of the superior longitudinal sinus may be delayed.

B. Electroencephalography. No electrical activity during at least 30 minutes of recording that adheres to the minimal technical criteria for EEG recording in suspected brain death as adopted by the American Electroencephalographic Society, including 16channel EEG instruments.

C. Transcranial Doppler ultrasonography

1 . Ten percent of patients may not have temporal insonation windows. Therefore, the initial absence of Doppler signals cannot be interpreted as consistent with brain death.

2. Small systolic peaks in early systole without diastolic flow or reverberating flow, indicating very high vascular resistance associated with greatly increased intracranial pressure.

D. Technetium-99m hexamethylpropyleneamineoxime brain scan. No uptake of isotope in brain parenchyma ("hollow skull phenomenon"). 
E. Somatosensory evoked potentials. Bilateral absence of N20-P22 response with median nerve stimulation. The recordings should adhere to the minimal technical criteria for somatosensory evoked potential recording in suspected brain death as adopted by the American Electroencephalographic Society.

\section{Medical record documentation (Stan- dard)}

A. Etiology and irreversibility of condition

B. Absence of brainstem reflexes

C. Absence of motor response to pain

D. Absence of respiration with $\mathrm{PCO}_{2} \geq 60 \mathrm{~mm} \mathrm{Hg}$

E. Justification for confirmatory test and result of confirmatory test

F. Repeat neurologic examination. Option: the interval is arbitrary, but a 6-hour period is reasonable.

\section{Acknowledgments}

The Quality Standards Subcommittee wishes to express particular gratitude to Eelco F.M. Wijdicks, MD, for his work in preparing the background paper as well as this summary statement. Jasper R. Daube, MD, served as facilitator for this project. The Quality Standards Subcommittee thanks the Ethics and $\mathrm{Hu}$ manities Subcommittee and the fifteen members of the AAN Member Reviewer Network who reviewed and returned comments on these practice parameters. The Subcommittee appreciates the reviews of several other critical care specialists.

Quality Standards Subcommittee: Jay H. Rosenberg, $M D$ (Chair); Milton Alter, $M D, P h D$; Thomas N. Byrne, $M D$; Jasper R. Daube, MD; Gary Franklin, MD, MPH; Benjamin Frishberg, MD; Michael L. Goldstein, MD; Michael $K$. Greenberg, MD; Douglas J. Lanska, MD; Shrikant Mishra, MD, MBA; Germaine L. Odenheimer, MD; George Paulson, MD; Richard A. Pearl, MD; and James Stevens, $M D$.

Medical societies invited to comment on these practice parameters: the American Academy of Family Physicians (which provided comment), the American Association of Neurological Surgeons, and the American Academy of Pediatrics.

\section{DEFINITIONS}

\section{Classification of evidence}

Class I. Evidence provided by one or more well-designed, randomized, controlled clinical trials.

Class II. Evidence provided by one or more well-designed clinical studies such as case-control and cohort studies.

Class III. Evidence provided by expert opinion, nonrandomized historical controls, or one or more case reports.

\section{Strength of recommendations}

Standards. Generally accepted principles for patient management that reflect a high degree of clinical certainty (ie, based on class I evidence or, when circumstances preclude randomized clinical trials, overwhelming evidence from class II studies that directly addresses the question at hand or from decision analysis that directly addresses all the issues).

Guidelines. Recommendations for patient management that may identify a particular strategy or range of management strategies and that reflect moderate clinical certainty (ie, based on class II evidence that directly addresses the issue, decision analysis that directly addresses the issue, or strong consensus of class III evidence).

Practice options or advisories. Strategies for patient management for which clinical certainty is lacking (ie, based on inconclusive or conflicting evidence or opinion).

Practice parameters. Results, in the form of one or more specific recommendations, from a scientifically based analysis of a specific clinical problem.

This statement is provided as an educational service of the American Academy of Neurology. It is based on an assessment of current scientific and clinical information. It is not intended to include all possible proper methods of care for a particular neurologic problem or all legitimate criteria for choosing to use a specific procedure. Neither is it intended to exclude any reasonable alternative methods. The AAN recognizes that specific decisions on patient care are the prerogative of the patient and the physician caring for the patient and are based on all the circumstances involved. Regardless of the conclusions of this statement, the Quality Standards Subcommittee of the AAN recognizes the need to comply with state law. 


\section{Neurology}

\section{Practice parameters for determining brain death in adults: (Summary statement) \\ Neurology 1995;45;1012-1014 \\ DOI 10.1212/WNL.45.5.1012}

\section{This information is current as of May 1, 1995}

\section{Updated Information \& Services}

\section{Citations}

Permissions \& Licensing

Reprints including high resolution figures, can be found at: http://n.neurology.org/content/45/5/1012.citation.full

This article has been cited by 34 HighWire-hosted articles: http://n.neurology.org/content/45/5/1012.citation.full\#\#otherarticles

Information about reproducing this article in parts (figures,tables) or in its entirety can be found online at:

http://www.neurology.org/about/about_the_journal\#permissions

Information about ordering reprints can be found online: http://n.neurology.org/subscribers/advertise

Neurology ${ }^{\circledR}$ is the official journal of the American Academy of Neurology. Published continuously since 1951, it is now a weekly with 48 issues per year. Copyright Copyright 1995 by Advanstar Communications Inc.. All rights reserved. Print ISSN: 0028-3878. Online ISSN: 1526-632X.

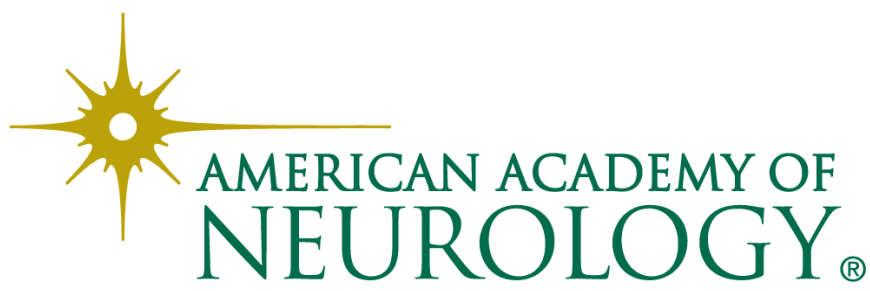

